\title{
An Assessment to Replace Conventional Mild Steel with Hybrid Nanocomposite Steel to Improve Mechanical and Anticorrosive Properties
}

\author{
Sandeep.V.Gujjar, Chaitali.R.Kulkarni, Shivani.G.Khabale, Usha.N.Mane, Anand. M. Hunashyal
}

\begin{abstract}
Multi Walled Carbon nanotube's (MWCNT's) are tiny tube's made of carbon atoms with a few nanometers in diameters and several microns in length. After Iijima's discovery in 1991, regarding the form of carbon atoms, a great deal of interest was drawn to utilize of MWCNTs outstanding chemical and physical properties such as high Young's tube, tensile strength, excellent thermal and electrical conductiveness. Recently, MWCNT's have been used in various fields, due to high chemical, thermal and mechanical properties. In the field of composite structures in which MWCNT's are not only included in a matrix as an insulation but also to obtain other chemical and physical properties like corrosion resistance, mechanical properties and electrical conductivity. Multi walled carbon nanotube's along with other nanoparticle's such as grapheme oxide, zinc oxide, silicon oxide and cerium oxide nano particles which have been proven to have better mechanical and anticorrosion properties incorporated independently with MWCNT's to develop hybrid nanocomposite's offering a new composite material generation. Nanostructured composites enhance their sensitivity and efficiency when used in corrosive environment. In this research study an attempt is made to introduce new hybrid nanocomposite steels which can have higher mechanical and anticorrosive properties.
\end{abstract}

Keywords: MWCNT, Mild steel, Mechanical properties, Nanocomposites

\section{INTRODUCTION}

Due to the high resistance to corrosion and oxidation resistance properties mild steel is widely used as an engineering material. The internal microstructure and external environmental condition decides the mechanical properties of metallic materials [17-19]. Steel is used for various applications such as hammer, mills, ball bearings, drills, etc. By the addition of MWCNT's mechanical properties of mild steel have been increased [3-5]. Increasing carbon nanotube's content by 1-3\% improving hardness and therefore density become less [5]

Revised Manuscript Received on April 04, 2020.

* Correspondence Author

Sandeep.V.Gujjar*, Assistant Professor, Department of Civi Engineering, Pillai HOC College of Engineering and Technology, Rasayani, Dist.Raigad-410207, Maharashtra, India.

Chaitali R., Civil Engineering from Pillai HOC College of Engineering and Technology, Rasayani, Dist.Raigad-410207, Maharashtra, India.

Shivani G. Khabale, Civil Engineering, Pillai HOC College of Engineering and Technology, Rasayani, Dist.Raigad-410207, Maharashtra, India.

Usha N. Mane, Civil Engineering, Pillai HOC College of Engineering and Technology, Rasayani, Dist.Raigad-410207, Maharashtra, India.

Dr. Anand. M. Hunashyal, Associate Professor, Department of Civil Engineering, Visvesvaraya Technological University, KLE Institute of Technology, Hubballi-580021, Karnataka, India.

(C) The Authors. Published by Blue Eyes Intelligence Engineering and Sciences Publication (BEIESP). This is an open access article under the CC BY-NC-ND license (http://creativecommons.org/licenses/by-nc-nd/4.0/)
Commercially available 316L austenitic stainless steel powder was used to prepare samples consisting of $\mathrm{Ni}-2.5 \%$ Mo-1.5 \% Fe-16.8 \% Mn-0.6 \% Cr-12\% Si (wt. \%).

The dispersion process of composites was multiwalled carbon nanotube's (MWCNT's) (firm: Nanocyl, Belgium) with a thickness of $5 \mathrm{~nm}$ and a length of several tens of micrometers. First, the DMQ-07 attritor (firm: Union Process) effectively milled the starting $316 \mathrm{~L}$ powder in propanol for $10 \mathrm{~h}$ at $2800 \mathrm{rpm}$. In this unit, stainless steel rig by means of delta disk agitators was utilized. About $1 \mathrm{~mm}$ diameter stainless steel grinding balls was used. The powder was milled in a dry environment for 1 hour at 600 rpm in the 01-HD / HDD M attritor after sifting in a $100 \mathrm{~m}$ mesh.1 and 3 wt after this milling process percent MWCNT's were mixed with the 316L powder and was further milled in the 01-HD / HDDM type attritor with a stainless steel tank, $1 \mathrm{~mm}$ diameter grinding medium and a delta disk agitator. High energy milling was carried out for 3 hours in ethanol solution at $4000 \mathrm{rpm}$ to ensure effective dispersion of multi walled carbon nanotube's in industrial 316L powder. At the end, the milled powder was shifted to a mesh of $100 \mathrm{~m}$. Reference sample 316L content was also developed without the addition of MWCNT's. This powder was also subjected to the same process of milling cycle as 316L powder and MWCNT's mixtures. The powders formed were sintered by SPS at a vacuum of $900 \pm 10^{\circ} \mathrm{C}$ for $5 \mathrm{~min}$ at a load of $50 \mathrm{MPa}$. The SPS method was carried out by a SPS-7.40 MK-VII system (firm: SPS Syntex Inc.) manufactured at Istanbul Technical University using a current of 20,000. After the consolidation process, disks having diameter of $50 \mathrm{~mm}$ and a thickness of $5 \mathrm{~mm}$ was made. Samples obtained from pure 316L are referred to as 316L, 316L-1CNT and 316L-3CNT, respectively, in mixtures of 316L and 1 and 3 wt. Percent of MWCNT [20].

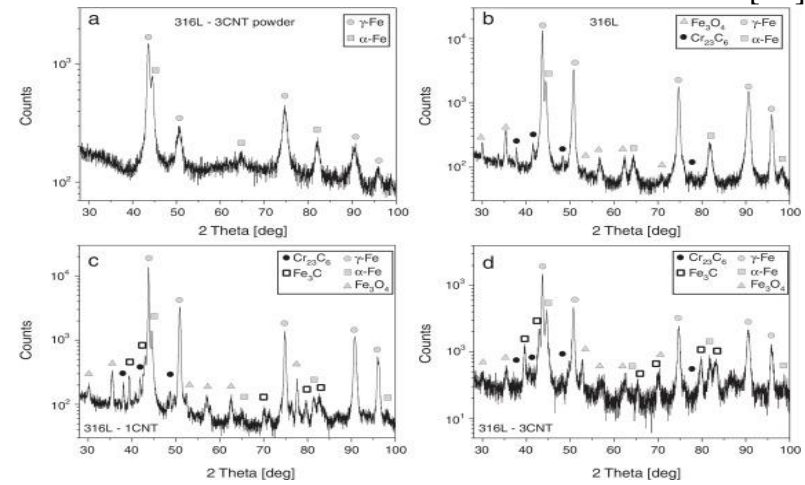

Fig.1 X-ray diffraction diagrams for (a) the original 316L-3CNT powder blend samples, (b) The sintered 316L powder samples, (c) 316L-1CNT samples and (d) 316L-3CNT samples [20]

Published By:

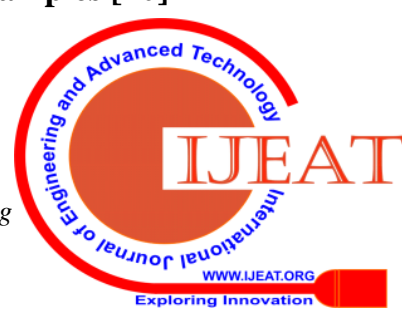


Table.1. Three point Bending Strength

\begin{tabular}{|c|c|c|}
\hline $\begin{array}{c}\text { Composition of } \\
\text { samples }\end{array}$ & HV in GPa & $\begin{array}{c}\text { Three point bending } \\
\text { strength in MPa }\end{array}$ \\
\hline 316L sample & $3.5 \pm 0.2$ & $1324.00 \pm 28.00$ \\
\hline $\begin{array}{c}\text { 316L-1CNT } \\
\text { sample }\end{array}$ & $4.6 \pm 0.4$ & $1237.00 \pm 91.00$ \\
\hline $\begin{array}{c}\text { 316L-3CNT } \\
\text { sample }\end{array}$ & $5.7 \pm 0.5$ & $866.00 \pm 67.00$ \\
\hline
\end{tabular}

By adding $1 \%$ wt. of MWCNT's to 316L steel, hardness property increased from $3.5 \pm 0.2$ to $4.6 \pm 0.4$ in GPa. Increasing the MWCNT's value ranging from 1 to 3 wt. as a percentage, the hardness increased to $5.7 \pm 0.5$ in GPa. Along with the hardness, three point bending strength property values for the sintered samples of steel are shown in Table.1. The nanostructured steel samples show a very high tensile strength property of $1400 \mathrm{MPa}$, with a limited tensile ductility (about 2\% uniform elongation)[19].

The rise in MWCNT's content from 1 to $3 \%$ by wt. did not produce a little grain size or a higher disorder rate. Most possibly, the grouping of the MWCNT's in the 316L-3CNT sample minimised the impedimental effect on recovery as well as the recrystallization of a unit amount of MWCNT's. Because of hardening effect of the MWCN's, the $\mathrm{Fe} 3 \mathrm{C}$ process, the little grain size and the higher dislocation density, the additional MWCNT's improved the durability of the sintered 316L Alloy. The clustering of MWCNT's resulted in a weak bond between the 316L grains, which resulted in a significant decrease in the bending strength by 3\% of MWCNT's [20].

Aluminium matrices are becoming more common in various uses such as automotive, aerospace, sports equipments because of their improved stiffness and strength, as well as their light weight properties and high anticorrosion property compared to other nonferrous metals. Reinforcements which can facilitate the enhancement of the mechanical properties of the metal [3, 6, 24]. Alloys, Nano carbon materials (i.e., multi walled carbon nanotube's (MWCNT's), graphene, etc.) reinforced with $\mathrm{Al}$ or its alloy matrix Nano composites were produced to overcome the restrictions of the mechanical, high-temperature resistant properties of the casting currently in use [25]. Many methods of manufacturing MWCNT's / Al composites have been developed, such as friction stir-processing (FSP), high energy ball friction (HEBM) [21], and flake powder metallurgy (Flake PM). As a result 1.5 and 3 vol\% CNT / Al composites were produced through a powder metallurgy method[22-23], resulting in significantly increased tensile strength due to uniform distribution and minimal structural damage to MWCNT's as well as a bonded MWCNT-Al interface.

The Flake PM method showed great benefits in the uniform dispersion of high nano-reinforcement content in the Al nanoflakes.

The dispersion method is based on slurry. Thickness of $500 \mathrm{~nm} \mathrm{Al} \mathrm{nanoflakes} \mathrm{were} \mathrm{prepared} \mathrm{by}$ grinding a ball with pure water-atomized of spherical Al powder (10 mm diameter, 99.8 per cent purity) in absolute ethyl alcohol solution at $99 \mathrm{rpm}$ in for $4 \mathrm{~h}$ in a $1 \mathrm{~L} \mathrm{Lab}$ Stirring attritor steal balls with $6 \mathrm{~mm}$. MWCNT's, created by chemical vapour deposition method and is functionalized by carboxyl (diameter: 30e50 nm,-COOH content: $0.73 \mathrm{wt}$ per cent, purity $>95 \%$, length: $0.5 \mathrm{e} 2 \mathrm{~mm}$, Chengdu Organic Chemistry Co. Ltd., China) were then dispersed in deionised water with sodium dodecyl sulfate (SDS) as dispersing agent in ultrasound for 2 hours. The hydrophilic PVAmodified $\mathrm{Al}$ nanoflakes was then stirred in water to produce powdered slurry. The aqueous suspension of the MWCNT's was then applied to the slurry and then mechanical stirring was continued until the top solution was clear. The prepared for 2 percent by wt. (takes CNT density as $1.8 \mathrm{~g} / \mathrm{cm} 3$, the CNT volume fraction is about 3 vol. per cent) MWCNT's / $\mathrm{Al}$ powders was vacuum dry method and then heated in flowing argon $500 \mathrm{C}$ to eliminate PVA for 2 hours.

The ball milling with high energy and consolidation processes was carried out. This is the $3 \mathrm{vol}$. \% MWCNT's / Al nanoflake powders was mounted in $1 \mathrm{~L}$ stainless steel assimilation jars comprising $6 \mathrm{~mm}$ steel balls with a 20:1 ball to the powder weight ratio to crack the native $\mathrm{Al} 2 \mathrm{O} 3$ skin that was easily created during powder compaction or drying. The jar was then packed with argon and agitated at a rate of 426 rpm for 2 hours, using a planetary ball drill. Composite powders were gradually compressed into tubes (F40 $30 \mathrm{~mm}$ ) in die steel and condensed at $530 \mathrm{C}$ for 2 hours by vacuum hot pressing at $500 \mathrm{MPa}$, followed by hot extrusion at $4900 \mathrm{C}$ with a ratio of 20:1 (denoted as FPM-2hour 3 vol. \% MWCNT's / Al, for short)[7,15,16,17].

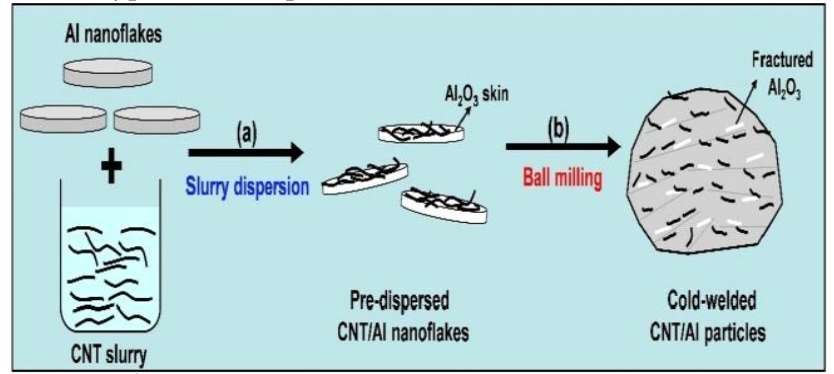

Fig.2. Illustration diagram showing fabrication of MWCNT's/Al composites using Flake PM Method [7]

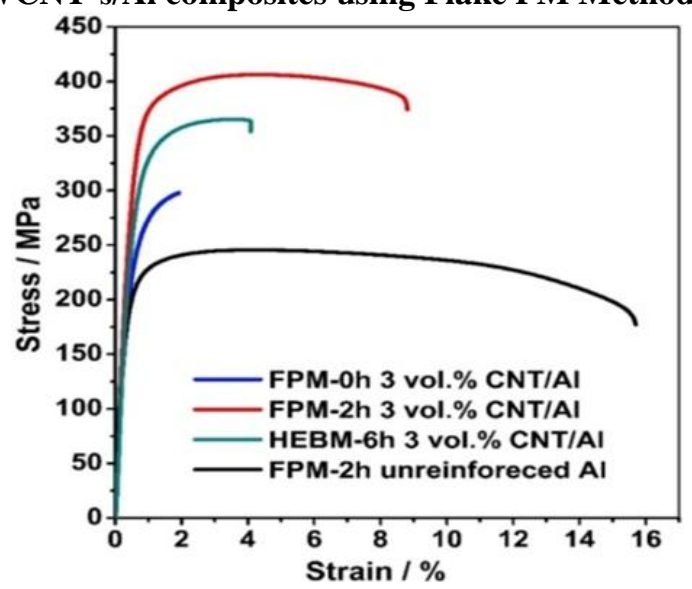

Fig.3.Tensile stress-strain curves

Fig.3. shows the tensile stress-train curve of 3 vol. The percent MWCNT's / Al composites prepared on different unreinforced and routes of the $\mathrm{Al}$ sample [7].

MWCNT's can be further homogeneously dispersed and the bonding between MWCNT's and Al can be strengthened from non-bonding to physical bonding and partial bonding to reaction. As a result 3 vol. the percentage of CNT / Al composites showed superior mechanical properties along with a tensile strength increased by 65.70 $\%$, and the modulus of elasticity was increased by $28.90 \%$ in comparison with $\mathrm{Al}$ matrix with a fine ductility of $8.80 \%$.

Published By:

Blue Eyes Intelligence Engineering

\& Sciences Publication

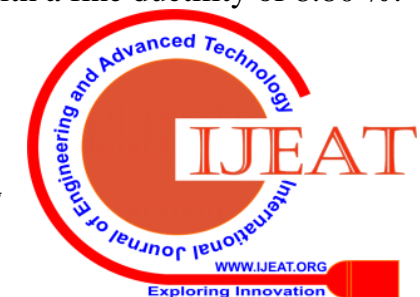


The consecutive enhancement of tensile strength, ductility and Young's modulus shows that both homogeneous MWCNT's dispersion and good interface bonding could be achieved through the method of Flake PM comprising of the slurry-based dispersion method and the short-term ball friction processes [7].

Flake PM enables the production of a strong and ductile CNT / Al composite with a tensile strength of 435 $\mathrm{MPa}$ and a plasticity of 6 per cent, which greatly exceeds the values of conventionally produced materials [22].

Graphene oxide nano particles are two dimensional materials with sp2 hybridized carbon atoms showing unique thermal, mechanical and electrical properties. It has a very good young's modulus with fracture strength of $125 \mathrm{GPa}$. Achievable method to harness extraordinary properties of the graphene for application can be done by dispersion of graphene in different kinds of material matrices [9,10 ]. Thus, implanting graphene sheets and platelets of a few layers into metal matrices is the newest and most effective way to produce high strength, Young modulus and hardness metallic materials. In particular, weight fractions / lowvolume of metal-graphene nano composites have dramatically increased strength and hardness. Ultimately, remember that the fabrication of metal-graphene nano composite's for more hardness, an elastic and strength properties is in its infancy. Future scope, is to expect exponential progress in the discovery, development and application of nano composite's, the potential of which is enormous for the transformation of so many technologies.

The development of graphene-metal composites has a variety of motivations. The graphene nano particle reinforcement mechanism is considered to be related to its outstanding mechanical and special organized characteristics and to the strong edges among graphene bonding and matrix bonding. There are lots of challenges concerned in the integration of graphene dispersion in the metal matrix with current traditional metallurgical processes or methods because of the enormous difference in density between metal matrix and GNFs, other interfacial contact part than the multi walled carbon nanotube's, and also the reaction on the matrix reinforcement edge as metals are highly responsive [26].The research relating to this field is still in its formative years. Yet increasing publications in this field means increasing interest in metal composites based on graphene.

In order to convert the GNS-adsorbed $\mathrm{Al}$ flakes into bulk composites, sintering, powder compacting and hot extrusion was carried out. The tensile property improved from 154 to the value of $249 \mathrm{MPa}$, with inclusion of just 0.3 wt. Percent GNS and a even elongation of 13 per cent remained, indicating that GNS's are most promising as an efficient reinforcement for the $\mathrm{Al}$ matrix composite. of four steps:

The novel approach, based on Flake PM, consists

(1) Production of aqueous dispersion of GOs. Graphite oxide (95\% purity, $0.1 \mathrm{~g}$ ) was included to the deionised water (about $200 \mathrm{ml}$ ) and then solution was ultrasonicated until brown colour, which shows the GO was exfoliated into single-layer or multi-layer nanosheets.

(2) Production and Surface Modification of the Al Flakes. The circular $\mathrm{Al}$ powder (10 $\mathrm{lm}$ in diameter, 99 per cent purity) was converted to $2 \mathrm{~lm}$ wide $\mathrm{Al}$ flakes in the attritor by $325 \mathrm{rpm}$ by ball milling. The Al flakes further processed in a 3 wt aqueous solution. Percent PVA to create a hydrophilic PVA layer on the face of Al flakes.

(3) Removal and adsorption of the GO nanosheet. PVA-customized Al flakes were applied to deionised water for the production of powdered slurry, followed by the introduction of GO nano particles in aqueous dispersion by drop wise. The blended slurry was manually stirred till its colour converted from dark to white before it was washed and rinsed using deionised water to collect $\mathrm{GO} / \mathrm{Al}$ composite powders.

(4) Compacting and consolidating carbon powders of GNS / Al. GNS / Al combination composite powders was compacted to U40 $30 \mathrm{~mm}$ tubes condensed by sintering in the Ar atmosphere for 2 hours at $5800 \mathrm{C}$, followed by the hot extrusion to $4400 \mathrm{C}$ with ratio 20:1. The pure $\mathrm{Al}$ specimen were also prepared for analysis using flaky $\mathrm{Al}$ powder using the same process.

The composite with an additional GNS with 0.3 wt. per cent showed a tensile property enhancement of 62 per cent compared to unreinforced matrix, and also uniform elongation above 5 per cent engineering standard [12]. It can be observed that the significant advantage of the GNFs/Metal matrix nanocomposite's compared to usual metal matrix composites. The enormous potential for composite reinforcement production with Graphene showing significant properties with high level of stiffness and strength indicates that the result of the composite will have excellent mechanical properties [9].

Silicon nano particles have different processing routes and related mechanical properties of silicon carbide/nitride reinforced metal matrix nanocomposite's (MMNCs). Physical and mechanical properties that can be obtained from Metal Matrix Nano Composites (MMNCs) have made them potential candidates for use in aerospace and automotive applications. MMNCs are rendered by dispersing into a metal matrix a ceramic substance. Because of their low costs and improved facilities MMNCs have attracted attention. Carbides, nitrides and oxides are used in various substitutes. The silicon carbide reinforced metal matrix nanocomposites is considered to be a potential candidate for heavy duty applications [27].

For sample preparation two different methods of sintering were applied:

(1)The prepared powder was added to an ethanol solution bath for hot isostatic pressing (HIP-type ABRA) and was sonicated for 1 hour. Polyethylene glycol (PEG) was used after sonication. The batches were sifted through a mesh of $150 \mathrm{~mm}$. Green samples were collected by dry pressing at $220 \mathrm{MPa}$. In order to remove PEG, an oxidation method was performed at heating level of about $4000 \mathrm{C}$. The sintering technique was performed for 3 hours in presence of high-purity nitrogen gas at $17000 \mathrm{C}$ and $20 \mathrm{MPa}$ pressure and $\mathrm{BN}$ embedding material was used. Heating rates were no higher than $250 \mathrm{C} / \mathrm{min}$. The measurements of the assintered specimen samples were about $3.5 \mathrm{~mm}, 5 \mathrm{~mm}$ and $50 \mathrm{~mm}$.

(2) Spark plasma technique of sintering method was done in vacuum by a Dr. Sinter 2050 device (Sumitomo Coal Mining). The powder combinations were fitted with an inner diameter of $10 \mathrm{~mm}$ in cylindrical carbon dies. The specimens were then heated with a pulsed d.c.

Published By:

Blue Eyes Intelligence Engineering 
The Current that guaranteed a heating rate of 1000 $\mathrm{C} / \mathrm{min}$ for all experiments was used. The temperature increased to $600 \mathrm{0C}$ for duration of $3 \mathrm{~min}$ and the optical pyrometer based on the die surface was controlled and monitored from that point onwards. From the beginning till the conclusion of the sintering process, a pressure of either $100 \mathrm{MPa}$ or $50 \mathrm{MPa}$ was carried out. Fast maintenance time, from 3 to $5 \mathrm{~min}$. The system allowed a cooling rate of approximately 400 8C / min between 1650 and 1000 8C. Samples with a diameter of $10 \mathrm{~mm} 5 \mathrm{~mm}$ were collected [28].

Although the samples were sintered by the method of spark plasma sintering process consist of alpha Si3N4 and are therefore stiffer and softer, the hot-isostatic composites discern beta Si3N4 grains and provide tougher composites. $\mathrm{P} / \mathrm{M}$ process is one of the most economical techniques for producing better structural and mechanical properties of quality MMNC products. It was found from SiC's study of reinforced $\mathrm{Mg}$ composites that tensile strength and elasticity modulus are increasing [27].

Due to its various remarkable properties (pyroelectric and piezo), a broad range of high photostability, UV absorption, biodegradability and biocompatibility, zinc oxide is a multifunctional content. $\mathrm{ZnO}$ nano particles can also be derived from a collection of particle structures that define its utilization in a wide range of technology fields in new materials and potential applications. The production of a crystalline zinc oxide synthesizing method that can be utilized on an industrial point of view and therefore becoming a subject of interest in both industry and science.

Improved MWCNT content resulted in higher conductivity, associated with zinc-based cathodic protection of carbon steel. Adding MWCNTs improved the adhesion power of epoxy zinc coatings, making this effect more evident following hydrothermal cyclic testing. Corrosion frequency on the epoxy zinc-coated carbon steel surface decreased as the zinc and MWCNT contents increased [33].

The use of an organic layer barrier on the exterior surface that break up steel from the corrosion environment is an effective process for anticorrosion of steel structures. An anticorrosion potential of the polymer coating on the steel substrate is determined not merely by the chemical composition, but also by the metal bonding strength / interfacial polymer [31].

The major effective way to avoid mild steel from corrosion is by having an impermeable covering over it. The cerium oxide nano particles exhibited good performance in $\mathrm{HCl}$ and $\mathrm{H} 2 \mathrm{SO} 4$ solution media as a corrosion inhibitor. The average cerium oxide inhibition performance was 83.55 percent in $1 \mathrm{~N} \mathrm{HCl}$ and 99.73 percent in $1 \mathrm{~N} \mathrm{H} 2 \mathrm{SO} 4$, respectively in 24 hour of normal temperature immersion time. Nonetheless, inhibition performance improved at room temperature with concentration of inhibitors from 0.05 per cent for 24 hours. It can be concluded from the comparative studies, the inhibitor output is higher in $\mathrm{H} 2 \mathrm{SO} 4$ than in $\mathrm{HCl}$, as sulphuric acid is a dibasic acid, which stimulates the corrosion rate of mild steel [32].

The MWCNT nano particles along with the newly developed nano particles such as grapheme oxide nano particles, zinc oxide nano particles, silicon oxide nano particles and cerium oxide nano particles have proven to have a better mechanical and corrosion resistance properties.

\section{TEST AND DISCUSSION:}

Production of nanoparticles: Ammonium cerium nitrate (IV) products, ammonia solution, citric acid, sulphuric acid and hydrochloric acid etc., obtained from EMerck was used. Without further purification reagents and solvents was used.

Preparation of cerium oxide $(\mathrm{CeO})$ nanoparticles: Cerium oxide nanoparticles were prepared using the citric acid and ammonium cerium (IV) nitrate precursor combustion process. In $50 \mathrm{ml}$ of distilled water $4.2 \mathrm{gm}$ of citric acid $(0.02 \mathrm{M})$ and $4 \mathrm{gm}$ of ammonium cerium (IV) nitrate $(0.01 \mathrm{M})$ were dissolved and vigorously mixed for 20 minutes. During mixing of ammonia, the solution was slowly added drop wise, and the solution $\mathrm{pH}$ value was increased to 10 . The obtained solution was heated on a hot plate, with frequent mixing. Self-combustion occurs after some time. The ash formed was collected for a period of 3 hours and calcinated at 300 0C in the furnace.

Corrosion inhibition - specimen preparation: The mild steel were cut into small pieces of $1 \mathrm{~b}(52 \mathrm{~cm})$ and picked in a pickling solution (5\% H2SO4) for 3 minutes and then washed using distilled water. Once the steel sample plates were dry, they were coated with different types of emery paper and deteriorated using acetone solution. The specimen weights were recorded and then submerged in test solution comprising different concentrations of nanoparticle's in $1 \mathrm{~N} \mathrm{HCl}$ and H2SO4.The specimens were removed from the test solutions after a period of 24 hours in $\mathrm{HCl}$ and $\mathrm{H} 2 \mathrm{SO} 4$ and washed thoroughly with distilled water, dried and finally weighed. Weight differences were noted in the calculation of the inhibition efficiency (IE) and corrosion rate (CR) using the below equation,

$$
\mathrm{CR}=\text { 87.6WAT/DAT }
$$

Where D, W, A and T represent metal density in $\mathrm{g} /$ $\mathrm{cm} 3$, weight loss in $\mathrm{mg}$, the, sample region in $\mathrm{cm} 2$ and the metal sample exposure period in hours, respectively. Similarly, performance Calculated inhibitions using equation,

$$
\% \mathrm{IE}=[\mathrm{W} 0-\mathrm{Wi}] / \mathrm{W} 0
$$

Where, W0 and Wi are values for weight loss in grams of mild steel in the absence and presence of a corrosion inhibitor, respectively.

Acidic baths preparation using nanoparticles: the degree of corrosion of mild steel in $\mathrm{H} 2 \mathrm{SO} 4$ and $1 \mathrm{~N} \mathrm{HCl}$ in the absence and presence of nanoparticles have been checked by holding the different contents as below. For a period of 24 hours, two separate specimens of same size were dipped separately in a beaker at room temperature in $100 \mathrm{ml}$ solutions of $1 \mathrm{~N} \mathrm{HCl}$ and $1 \mathrm{~N} \mathrm{H} 2 \mathrm{SO} 4$. CeO2 nanoparticles were distributed independently in $100 \mathrm{ml}$ of 1 $\mathrm{N} \mathrm{HCl}$ and $1 \mathrm{~N} \mathrm{H} 2 \mathrm{SO} 4$ at different percentages $(0.05,0.10$, 0.20 and 0.40 ). In the presence of nanoparticles separately for a period of 24 hours at room temperature, a smooth, washed steel plate of the specimen samples were immersed in those acidic baths [32].

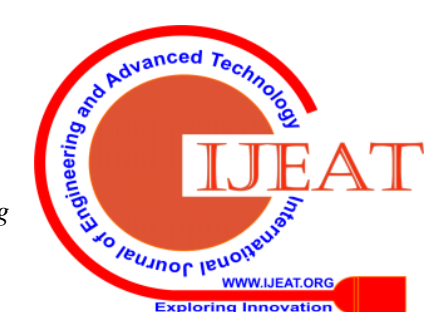



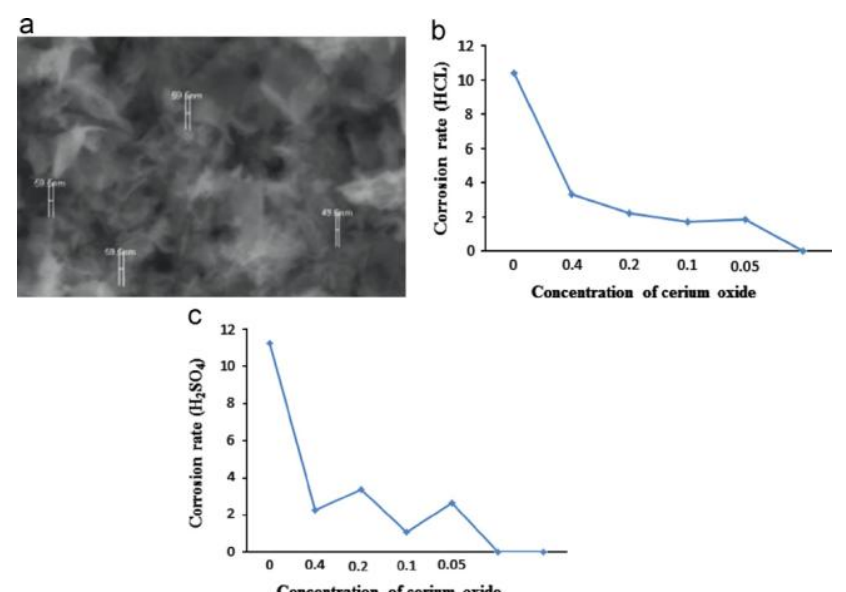

Fig. 4. (a) Image of $\mathrm{SEM} \mathrm{CeO}_{2}$ nano particles, Fig.4.(b) \& Fig.4. (c) Shows the highest corrosion inhibition efficiency of cerium oxide nano particle is about $83.55 \%$ in $1 \mathrm{~N} \mathrm{HCl}$ and $99.73 \%$ in $1 \mathrm{~N}_{2} \mathrm{SO}_{4}$ respectively and $\mathbf{0 . 1 \%}$ solution of inhibitor for 24 hours @ room temperature [32].
As a corrosion inhibitor, cerium oxide nano particles showed very good performance in presence of $\mathrm{HCl}$ and $\mathrm{H} 2 \mathrm{SO} 4$ solution media. The mean inhibition efficiency of CeO2 NPs was $83.55 \%$ in $1 \mathrm{~N} \mathrm{HCl}$ and 99.73 $\%$ in $1 \mathrm{~N} \mathrm{H2SO} 4$, respectively, in 24 hours of room temperature immersion time [32].

With this in mind, the impact of grapheme nanocomposite's is possibly to raise in future, and graphene will be altered from a material perfect for scientific research leading to new technologies, into an engineering material presenting important solutions to industrial and user needs. The composite material's properties derive from the evenly distribution of MWCNT's, interfacial bonding, MWCNT's weight level, volume, and matrix alignment. This research work discusses various processing techniques for MWCNT's-metal and MWCNT's-steel nanocomposite's, and also their recorded material and mechanical properties [3].

Table. 2 A recent application of graphene reinforced composite [9].

\begin{tabular}{|c|c|c|}
\hline $\begin{array}{l}\text { Sl. } \\
\text { No. }\end{array}$ & Composition & Properties and applications \\
\hline 1 & Pt-Graphene & $\begin{array}{l}\text { Super capacitor- fuel cell applications, Electrochemically } \\
\text { active surface area-Catalyst carrier in electro catalysis and fuel } \\
\text { cells applications }\end{array}$ \\
\hline 2 & $\mathrm{Al} / \mathrm{Pd} / \mathrm{Pt}$ & $\begin{array}{l}\text { Acts as catalytic methanol oxidation-Methanol fuel cell } \\
\text { applications }\end{array}$ \\
\hline 3 & Au-graphene & $\begin{array}{l}\text { DNA gets adsorbed faster than only Au surface Biosensors, } \\
\text { Biodevices and DNA Sequencing applications, } \\
\text { Voltammograms of electrolytic reduction of oxygen and } \\
\text { glucose oxidation shows more Au- Graphene than alone Au- } \\
\text { Fuel cell and bioelectroanalytical chemistry applications } \\
\text { Apparent electrode area Environmental monitoring - detection } \\
\text { of mercury, } \\
\text { Electroactive surface area- electrochemical detection of DNA } \\
\text { specific sequence applications }\end{array}$ \\
\hline 4 & Co-Graphene & Anode material for Li-ion battery applications \\
\hline 5 & Si-Graphene & Anode material for Li-ion battery applications \\
\hline 6 & $\begin{array}{l}\text { Al powder } \\
\text { graphene }\end{array}$ & $\begin{array}{l}\text { Graphene as reinforce -Strengthening of Composite } \\
\text { applications, } \\
\text { Decreased strength and hardness, } \\
\text { Lower failure strain and higher Vickers hardness }\end{array}$ \\
\hline 7 & $\begin{array}{l}\text { Mg-Graphene } \\
\text { based } \\
\text { composite }\end{array}$ & Production of Ultra high performance metal matrix composite \\
\hline 8 & $\begin{array}{l}\text { Cu-graphene } \\
\text { composite foil }\end{array}$ & $\begin{array}{l}\text { Higher the electrical conductivity and hardness compare to } \\
\text { copper alone }\end{array}$ \\
\hline 9 & $\begin{array}{l}\text { Mg-1\%A- } \\
1 \% \text { Sn } \\
\text { reinforced } \\
\text { graphene }\end{array}$ & $\begin{array}{l}\text { Superior Nano-filler adhesion and increased and tensile } \\
\text { strength }\end{array}$ \\
\hline 10 & $\begin{array}{l}\text { Au-Graphene- } \\
\text { HRP - CS }\end{array}$ & H2O2 Biosensor applications \\
\hline
\end{tabular}


The mechanical properties of nanocomposite are based on graphene and graphene were assessed. It is shown that the opportunities and capabilities of this category of materials for superior engineering applications are virtually endless because of their enhanced properties and also due to the presence of multifunctional graphene-based nano fillers. In view of this, the commercial impact of grapheme nanocomposite's is likely to raise in near future, and graphene will be altered by researchers leading to novel physics from a material ideal for scientific research into an engineering material presenting important solutions to the consumer and industrial needs [9,11,12].

\section{CONCLUSIONS}

In this paper it can be concluded that, preparing MWCNT composites with other nano particles such as graphane oxide, zinc oxide, silicon oxide and cerium oxide nano particles independently shows most promising composite to further enhance mild steel properties like mechanical and corrosion resistance instead of using only MWCNT's with mild steel composite. As the concentration of MWCNT's increases because of the attraction of van der Waals between MWCNT's and other nano-particle which induces agglomeration; it becomes more and more difficult to obtain a unvarying dispersion of nano-particles MWCNT, GO, $\mathrm{ZnO}, \mathrm{SiO}$ and $\mathrm{CeO}$. The resultant material characteristics can be a function of uniform dispersion of nano particles from MWCNT, GO, $\mathrm{ZnO}, \mathrm{SiO}$ and $\mathrm{CeO}$, interfacial bonding between MWCNT's and matrix, MWCNT's, GO, $\mathrm{ZnO}$, $\mathrm{SiO}$ and $\mathrm{CeO}$ weight, length and matrix alignment. In consequence, we depend on the device used and the processing parameters for optimisation composites, MWCNT's-GO-steel, MWCNT'sZnO-steel, MWCNT's-SiO-steel and MWCNT's-CeO-steel are the most promising structural materials of the next generation with prospective applications in several industries like the offshore petroleum industry. New, mechanically improved and anticorrosive composites may be used like a lightweight structural material suitable for offshore platforms and down-hole tubular like tubing, casing and down-hole tools for severe temperature and pressure implementation spark plasma sintering method. It is the greatest promising method among the different preparation methods, as the composite can be formed in a very short period of time and at a relatively low temperature, thereby minimizing the formation of defects. Though, much work has to be done before microstructure-property component and composite process optimization performance assessments can be carried out in real-world applications [3, 9].

\section{REFERENCES}

1. Mahmoud M Shokrieh, Ali Saeedi, Majid Chitsazzadeh, Mechanical properties of multi-walled carbon nanotube/polyester nanocomposites, Journal of nanostructure in chemistry, Springer, 3:20, 2013

2. A.Madhan Kumar, ZuhairM.Gasem, In situ electrochemical synthesis of polyaniline/f-MWCNT nanocomposite coatings on mild, steel for corrosion protection in 3.5\% $\mathrm{NaCl}$ solution, Elsevier, 2015, pp.-387394

3. Kristiina Oksman, Yvonne Aitomäki, Aji P. Mathew, Gilberto Siqueira, Qi Zhou, Svetlana Butylina, SupachokTanpichai, Xiaojian Zhou, Saleh Hooshmand, Review of the recent developments in cellulose nanocomposite processing, Composites: Part A (2015), Elsevier 2015, pp.1-53
4. Hyunwoo Kim, Shingo Kobayashi, Mohd A. AbdurRahim, Minglun J. Zhang, AlbinaKhusainova,,Marc A. Hillmyer, Ahmed A. Abdala, Christopher W. Macosko, Graphene/polyethylene nanocomposites: Effect of polyethylene functionalizationand blending methods, Elsevier, H. Kim et al. / Polymer 52 (2011), pp.1837-1846

5. Jiansheng Li1, Yang Cao, Bo Gao, Yusheng Li, , and YuntianZhu,mSuperior strength and ductility of 316L stainless steel with heterogeneous lamella structure, Springer,17 April 2018, pp.1-15

6. ShaghayeghShajaria,MohammadArjmand,ShitalPatangraoPawar,Utta ndaramanSundararaj, Les JozefSudaka, Synergistic effect of hybrid stainless steel fiber and carbon nanotube on mechanicalproperties and electromagnetic interference shielding of polypropylene nanocomposites, Elsevier, Composites Part B 165 (2019), pp.662-670

7. Genlian Fan , Yue Jiang , Zhanqiu Tan , QiangGuo , Ding-bang Xiong , Yishi Su , Renbang Lin, Li Hu, Zhiqiang Li, Di Zhang, Enhanced interfacial bonding and mechanical properties in CNT/Al composites fabricatedby flake powder metallurgy, Elsevier, Carbon 130 (2018), pp.333-339

8. Jin-zhi Liao, Ming-Jen Tan, Idapalapati Sridhar, Spark plasma sintered multi-wall carbon nanotube reinforced aluminum matrix composites, Elsevier, Materials and Design 31 (2010), pp.96-100

9. Prashantha Kumar H.Ga, M. Anthony Xavior, Graphene Reinforced Metal Matrix Composite (GRMMC): A Review, Elsevier, Procedia Engineering 97 (2014),pp.1033 - 1040

10. MuhammadRashada, FushengPana , AitaoTanga, Muhammad Asifd, Effect of GrapheneNanoplatelets addition on mechanical properties of pure aluminium using a semi-powder method, Elsevier, Progress in Natural Science: Materials International 24 (2014),pp. 101-108

11. Dimitrios G. Papageorgiou , Ian A. Kinloch, Robert J. Young, Mechanical properties of graphene and graphene-based nanocomposites, Elsevier, Progress in Materials Science 90 (2017), pp.75-127

12. I.A.Ovid'ko, Metal-graphenenanocomposites with enhanced mechanical properties: a review, Rev.Adv. Mater. Sci.38 (2014),pp. 190-200

13. Wang, J., Li, Z., Fan, G., Pang, H., Chen, Z. \& Zhang, D. Reinforcement with grapheme nanosheets in aluminum matrix composites ,ScriptaMaterialia, 66 (8) (2012), pp. 594-597.

14. NitinMuralidharan, EtiTeblum, Andrew S.Westover, Deanna Schauben,AnatItzhak, MeravMuallem, Gilbert D. Nessim\& Cary L. Pint, Carbon Nanotube Reinforced Structural Composite Supercapacitor, Nature, (2018) 8:17662

15. R. George, K.T. Kashyap, R. Rahul, S. Yamdagni, Strengthening in carbon nanotube/aluminium (CNT/Al) composites, Elsevier, ScriptaMaterialia 53 (2005), pp. 1159-1163

16. Robert J. Young, Ian A. Kinloch, Lei Gong, Kostya S. Novoselov, The mechanics of graphenenanocomposites: A review, Elsevier, Composites Science and Technology 72 (2012), pp. 1459-1476

17. X.H. Chen , J. Lu , K. Lu, Tensile properties of a nanocrystalline 316L austenitic stainless steel, Elsevier, ScriptaMaterialia 52 (2005), pp. 1039-1044

18. Ren-bo, XIANG Jian-ying, HOU Dong-po, Characteristics of Mechanical Properties and Microstructure for 316L Austenitic Stainless Steel, ScienceDirect, journal of iron and steel research, international. 2011, pp. 53-59

19. F.K. Yan, G.Z. Liu, N.R. Tao, K. Lu, Strength and ductility of 316L austenitic stainless steel strengthened by nano-scale twin bundles, Elsevier, ActaMaterialia 60 (2012),pp. 1059-1071

20. PéterJenei ,CsabaBalázsi ， ÁkosHorváthb, KatalinBalázsi JenoGubiczaa, The influence of carbon nanotube addition on the phase composition, microstructureand mechanical properties of 316L stainless steel consolidated by spark plasma sintering, 2018, pp. 1-9

21. A.M.K. Esawi , K. Morsi , A. Sayeda, A. Abdel Gawada, P. Borahb Fabrication and properties of dispersed carbon nanotube-aluminum composites, Elsevier ,Materials Science and Engineering A 508 (2009),pp. 167-173

22. Lin Jiang, ZhiqiangLi ,Genlian Fan, Linlin Cao, Di Zhang, The use of flake powder metallurgy to produce carbon nanotube (CNT)/aluminum composites with a homogenous CNT distribution, Elsevier , Carbon 50 (2012),pp. 1993 - 1998

23. Lin Jiang, Zhiqiang Li, Genlian Fan, Linlin Cao and Di Zhang, Strong and ductile carbon nanotube/aluminum bulk nanolaminated composites withtwo-dimensional alignment of carbon nanotubes, Elsevier, ScriptaMaterialia 66 (2012),pp. 331-334

24. I. Sridhar, Karthic R. Narayanan, Processing and characterization of MWCNT reinforced aluminum matrix composites, Springer, J Mater Sci (2009), pp. 1750-1756.

Published By:

Blue Eyes Intelligence Engineering

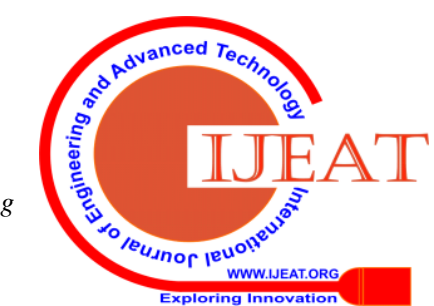


25. O. Carvalho , M. Buciumeanu , S. Madeira , D. Soares , F.S. Silva G. Miranda, Optimization of AlSi-CNTs functionally graded material composites for engine piston rings, Elsevier, Materials and Design 80 (2015), pp. 163-173

26. Prashantha Kumar HG and Anthony Xavior M, Processing of Graphene/CNT-Metal Powder, 2018, pp. 46-63.

27. AnmolDubey, PiyushKhosla, Himanshu Kumar Singh, Vishal Katoch, Devendra Kumar and PallavGupta

28. A Review on Role of Processing Parameter in Determining Properties of Silicon Carbide Reinforced, Metal Matrix Nanocomposites, Journal of Applied Science and Engineering, (2016), pp. 303-312 S Pasupuleti, R. Peddetti, S. Santhanam, K.-P. Jen, Z.N. Wing, M. Hecht,J.P. Halloran,Tougheningbehavior in a carbon nanotube reinforcedsilicon nitride composite, Elsevier, Mater. Sci.Eng. A 491 (1-2) (2008),pp.224-229

29. J. Dusza, J. Morgiel, P. Tatarko, V. Puchy, Characterization of interfaces in ZrO2-carbon nanofibercomposite,Scripta Mater, Elsevier,61 (3) (2009),pp.253-256.

30. O. Tapaszto ,P. Kun, F. Weber, G. Gergely, K. Balazsi, J. Pfeifer,P Arato, A. Kidari,S. HampshireC. Balazsi, Silicon nitride based nanocomposites produced by two different sintering methods, Elsevier,Ceramics International 37 (2011),pp. 3457-3461

31. GhasemBahlakeh, BahramRamezanzadeh,MohammadRamezanzadeh, Cerium oxide nanoparticles influences on the binding and corrosion protectioncharacteristicsof a melamine-cured polyester resin on mild steel: An experimental, densityfunctionaltheory and molecular dynamics simulation studies, Elsevier,2017,pp. 1-53.

32. R. Sharmila ,N. Selvakumar, K. Jeyasubramanian, Evaluation of corrosion inhibition in mild steel using ceriumoxide nanoparticles, Elsevier, Materials Letters 91 (2013) pp.- 78-80

33. SungMo Park, MinYoungShon,Effects of multi-walled carbon nano tubes on corrosionprotection of zinc rich epoxy resin coating,Elsevier,Journal of Industrial and Engineering Chemistry (2014),pp.1-7

\section{AUTHOR'S PROFILE}

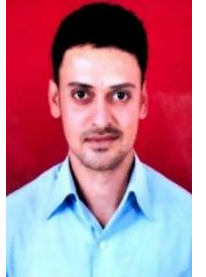

Sandeep.V.Gujjar is currently pursuing $\mathrm{PhD}$ from Visvesvaraya Technological University, Karnataka and working as an Assistant Professor in Department of Civil Engineering, Pillai HOC College of Engineering and Technology, Rasayani, Dist.Raigad-410207, Maharashtra, India. He has published books related to civil engineering, research papers, filed patents related to nano composite coating which enhances mechanical and anticorrosive properties of mild steel. He has guided several students pursuing post graduate and under graduate students for research work in civil engineering. He has more than 11 years of teaching, industry and research experience in Indian and international organization.

Ph: 8793169868, E-mail: sandeep.gujjar@rediffmail.com

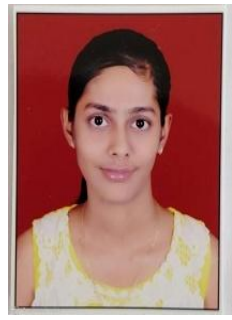

Chaitali R. is presently pursuing graduation in Civil Engineering from Pillai HOC College of Engineering and Technology, Rasayani, Dist.Raigad410207, Maharashtra, India. Presently working on research area of construction management and nano composite which enhances mechanical and anticorrosive properties of mild steel. She has done her internships in reputed civil engineering organization and also completed many software courses related to civil engineering. Ph: 8291706206,

E-mail: 16chaitalik@gmail.com

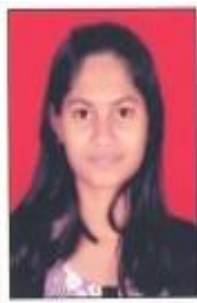

Shivani G. Khabale is presently pursuing graduation in Civil Engineering from Pillai HOC College of Engineering and Technology, Rasayani, Dist.Raigad-410207, Maharashtra, India. Presently working on research area of construction management and nano composite which enhances mechanical and anticorrosive properties of mild steel. She has done her internships in reputed civil engineering organization and also completed many software courses related to civil engineering. Ph: 9867758666,

Published By:

Blue Eyes Intelligence Engineering \& Sciences Publication

Usha N. Mane is presently pursuing graduation in Civil Engineering from Pillai HOC College of Engineering and Technology, Rasayani, Dist.Raigad-410207, Maharashtra, India. Presently working on research area of construction management and nano composite which enhances mechanical and anticorrosive properties of mild steel. She has done her internships in reputed civil engineering organization and also completed many software courses related to civil engineering. Ph: 9975267301

E-mail: ushamane8997@gmail.com

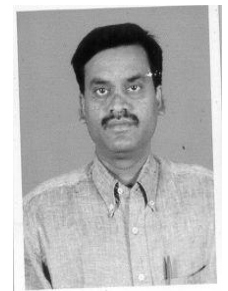

Dr. Anand. M. Hunashyal is presently working as an Associate Professor in the Department of Civil Engineering, Visvesvaraya Technological University, KLE Institute of Technology, Hubballi580021, Karnataka, India.He has completed his P.hD fromVisvesvaraya Technological University, Karnataka, India. $\mathrm{He}$ has published various research papers civil and mechanical engineering, filed and awarded patents related to nanocomposite coatings which enhance mechanical and anticorrosive properties of mild steel and many more. He is guiding several students pursuing doctorate, post graduate and under graduate students for research work in civil engineering. He has more than 20 years of teaching and research experience. Ph:9739192399, E-mail: amhunashyal@kletech.ac.in. 